\title{
Excision of Colloid Cyst through Interhemispheric, Transcallosal, Transcavum, Interfornicial Approach
}

\author{
Santosh Kumar ${ }^{1} \quad$ Nishanth Sadashiva ${ }^{1}$ \\ ${ }^{1}$ Department of Neurosurgery, National Institute of Mental Health \\ and Neurosciences, Bengaluru, India
}

\begin{abstract}
Address for correspondence Nishanth Sadashiva, MCh (Neurosurgery), Associate Professor, Department of Neurosurgery, National Institute of Mental Health and Neurosciences, Bengaluru 560029, Karnataka, India (e-mail: nishanth46@gmail.com).
\end{abstract}

\begin{abstract}
Keywords

- colloid cyst

- cavum septum pellucidum

- interfornicial approach
\end{abstract}

\section{Introduction}

Colloid cysts (CCs) occur predominantly in the midline with majority involving roof of the third ventricle. Approaches for CC are directed toward the Foramen of Monroe (FoM), and the first step after reaching the lateral ventricle after either transcallosal-interhemispheric or transcortical approach is to follow the choroid plexus to the foramen. In normal anatomic conditions, the trans-FoM approach is a safe method for reaching the roof and anterior part of the third ventricle to remove the lesion. In cases of cavum septum pellucidum (CSP), the surgeon can lose orientation when normal intraventricular structures are not encountered. ${ }^{1}$ Though forniceal injury may cause significant memory disturbances, when adequate space is available in the interfonicial space, this route may be used for excision of lesion.

A 39-year-old woman presented with history of severe headaches for 2 months. Evaluation with plain computed tomography (CT) of the brain showed a hyperdense lesion in the region of the FoM suggestive of CC with enlarged lateral ventricles. The presence of CSP was also noted ( - Fig. 1A, B). The patient underwent right frontal parasagittal craniotomy,

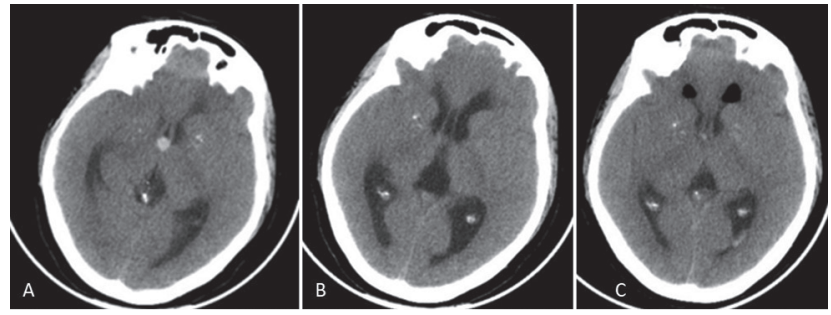

Fig. 1 (A) Computer tomography (CT) showing a hyperintense spherical lesion suggestive of colloid cyst in the region of the anterior third ventricle. (B) A coexisting cavum septum pellucidum (CSP) was noticed in the same scan. (C) Postoperative CT following excision of colloid cyst showing no residual lesion, with reduction in ventricle size and air in bilateral frontal horns.

interhemispheric, transcallosal approach to reach the lesion. After callosotomy, no ventricular landmarks were identified, and position within the CSP was understood by the flapping of its walls. Both fornices were slightly elevated and splayed, by the CC that was bulging upward from the third ventricular roof ( - Fig. 2). After opening the right-side flap of the CSP, the FoM was difficult to identify from the ventricular side as it was pushed laterally by the CC. Therefore, the CC published online April 19, 2021
DOI https://doi.org/

$10.1055 / \mathrm{s}-0039-3400208$ ISSN 2277-954X. (c) 2021. Neurological Surgeons' Society of India.

This is an open access article published by Thieme under the terms of the Creative Commons Attribution-NonDerivative-NonCommercial-License, permitting copying and reproduction so long as the original work is given appropriate credit. Contents may not be used for commercial purposes, or adapted, remixed, transformed or built upon. (https://creativecommons.org/licenses/by-nc-nd/4.0/).

Thieme Medical and Scientific Publishers Pvt. Ltd. A-12, 2nd Floor, Sector 2, Noida-201301 UP, India 


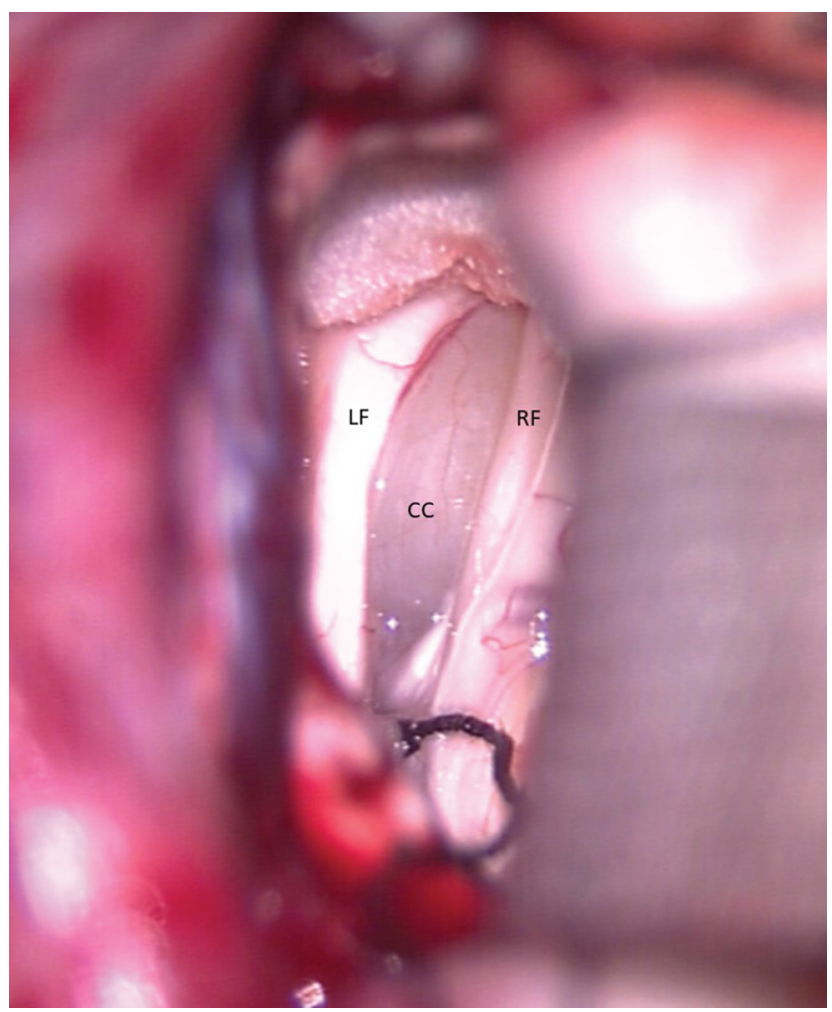

Fig. 2 Intraoperative view through the cavum septum pellucidum showing the colloid cyst (CC) bulging upward from the roof of the third ventricle splaying and displacing the right fornix (RF) and left fornix (LF) laterally.

was removed from the interfornicial approach with careful preservation of both fornices. The internal cerebral veins were identified posterior to the lesion after careful separation from the cyst wall. Postoperative period was uneventful, and postoperative CT scan showed complete excision of the lesion with reduction in ventricle size (-Fig. 1C).

Cavum septum pellucidum is a rare association with CC. Identifying CSP in preoperative images and understanding its relationship with the $\mathrm{CC}$ are essential to modify the operative approach, as in such cases the cyst may not be seen in its usual location of the FoM and entering the cavum may be confusing because no intraventricular landmarks will be seen. ${ }^{1,2}$ Excision of the cyst through the CSP usually requires interfornicial approach, and this structure must be separated gently to avoid injury. ${ }^{3}$ However, other routes must be carefully considered if the space between the fornices is less as interforniceal approach may not always be feasible or safe. ${ }^{3}$

\section{Funding \\ None.}

Conflict of Interest

None declared.

\section{References}

1 Sadashiva N, Sastry S, Bhat D, Pandey P. Operative nuances of excision of colloid cysts in septum pellucidum: a report of three cases. Neurol India 2014;62(6):665-668

2 Ciric I, Zivin I. Neuroepithelial (colloid) cysts of the septum pellucidum. J Neurosurg 1975;43(1):69-73

3 Timurkaynak E, Izci Y, Acar F. Transcavum septum pellucidum interforniceal approach for the colloid cyst of the third ventricle operative nuance. Surg Neurol 2006;66(5):544-547, discussion 547 